\title{
STUDY ON PREGNANCY OUTCOME IN PRETERM PREMATURE RUPTURE OF MEMBRANES WITH OLIGOHYDRAMNIOS
}

\author{
Supriya Kumari ${ }^{1}$, Chitra Sinha ${ }^{2}$, Chander Kiran ${ }^{3}$, Arpana Kumari ${ }^{4}$ \\ ${ }_{1}^{1}$ Postgraduate Student, Department of Obstetrics and Gynaecology, PMCH, Patna. \\ ${ }^{2}$ Associate Professor, Department of Obstetrics and Gynaecology, PMCH, Patna. \\ ${ }^{3} \mathrm{HOD}$, Department of Obstetrics and Gynaecology, PMCH, Patna. \\ ${ }^{4}$ Postgraduate Student, Department of Obstetrics and Gynaecology, PMCH, Patna.
}

ABSTRACT

\section{BACKGROUND}

Pregnancy outcome in preterm premature rupture of membranes is affected by AFI. PPROM with oligohydramnios $(\mathrm{AFI}<5)$ affects maternal outcome in terms of latency period, complications like chorioamnionitis, mode of delivery, and maternal sepsis. It also affects neonatal outcome in terms of neonatal weight, APGAR score, NICU admission, neonatal sepsis and neonatal death.

\section{MATERIALS AND METHODS}

This prospective observational study was carried in Department of Obstetrics and Gynaecology, Patna Medical College and Hospital, Patna, which included pregnant mothers attended and admitted through antenatal clinic OPD and Emergency of gestational age less than 37 weeks with complaining PPROM over a period of 2 years. Total 150 singleton pregnancies with PPROM without any other indications of immediate delivery or other cause of oligohydramnios were studied.

\section{RESULTS}

Incidence of PPROM was 2.6\%. Out of 150 Cases studied, 82 (54.6\%) were in group I (AFI<5) and 68 (45.33\%) were in group -II (AFI $\geq 5)$. The results showed that parity, gestational age at rupture, gestational age at the time of delivery, and mean of neonatal weight were almost equal. However, latency was significantly shorter in group I (AFI $<5)$ than in group II (AFI $\geq 5)$ with $p$ value of 0.001. Total no. of maternal sepsis cases was higher in group- I (3.6\%) as compared to group II (1.4\%). Out of 150 cases, 112 $(74.66 \%)$ delivered vaginally and $38(25.33 \%)$ delivered by LSCS. Foetal distress was significantly higher in group I (AFI $<5)$ compared to group II. (P value-0.021). Whereas failed induction was the most common cause of LSCS in group II (P value - 0.004). No. of neonates with first minute APGAR score $\leq 7$ was significantly higher in group I $(\mathrm{AFI}<5)$ compared to group II ( $\mathrm{p}=0.001)$. There was significant difference in NICU admission rate ( $p$ value 0.001), early neonatal sepsis ( $p$ value 0.021 ) and early neonatal death ( $p$ value 0.031 ).

\section{CONCLUSION}

Preterm premature rupture of the foetal membranes with oligohydramnios remains a major cause of preterm delivery, high rate of LSCS, shorter latency and high neonatal morbidity and mortality.

\section{KEYWORDS}

Preterm Premature Rupture of Membrane, Amniotic Fluid Index, Standard Deviation, Lower Segment Caesarean Section.

HOW TO CITE THIS ARTICLE: Kumari S, Sinha C, Kiran C, et al. Study on pregnancy outcome in preterm premature rupture of membranes with oligohydramnios. J. Evolution Med. Dent. Sci. 2017;6(62):4569-4571, DOI: 10.14260/Jemds/2017/988

\section{BACKGROUND}

Prelabour rupture of membranes (PROM) is the rupture of the foetal membranes before the onset of labour. In most cases, this occurs near term, but when membrane rupture occurs before 37 weeks gestation, it is known as preterm premature rupture of membranes (PPROM). Preterm PROM complicates approximately $3 \%$ of pregnancies and leads to one third of preterm birth. ${ }^{1}$ One of the most common complications of preterm PROM is preterm labour with all its complications.

Financial or Other, Competing Interest: None.

Submission 17-04-2017, Peer Review 25-05-2017,

Acceptance 01-06-2017, Published 03-07-2017.

Corresponding Author:

Supriya Kumari,

Room No 32,

Kasturba PG Hostel,

PMCH, Ashok Rajpath,

Patna-800004.

E-mail: supriyapmch@gmail.com

DOI: $10.14260 /$ jemds $/ 2017 / 988$
The latent period, which is the time from membrane rupture until delivery, generally is inversely proportional to the gestational age at which PROM occurs. When PROM occurs too early, surviving foetus may develop sequelae such as malpresentation, cord-compression, oligohydramnios, necrotising enterocolitis, neurologic impairment, intraventricular haemorrhage, and respiratory distress syndrome 2,3,4,5,6,7

Amniotic fluid buffers the foetus, allowing proper growth and development of lung and musculoskeletal system. It has bacteriostatic, anti-inflammatory properties, aids thermoregulation and averts compression of the umbilical cord especially in term pregnancy. ${ }^{8}$

Amniotic fluid plays an important role in foetal health and is far from being a stagnant pool as it was once thought. Amniotic fluid physiology is a dynamic process involving numerous forces and pathways influencing influx and efflux of fluid and solutes within amniotic fluid cavity and the regulating mechanism are yet to be completely understood. ${ }^{9}$ 
Acute oligohydramnios occurs from rupture of membranes, usually diagnosed by clinical signs of vaginal fluid with altered $\mathrm{pH}$ and fern pattern. ${ }^{10}$

\section{MATERIALS AND METHODS}

This prospective observational study was done in Department of Obstetrics and Gynaecology, Patna Medical College and Hospital over a period of 2 years on 150 patients and foetomaternal outcomes were concluded.

\section{Inclusion Criteria}

Pregnant mothers attended and admitted through antenatal clinic OPD and Emergency of gestational age less than 37 weeks with complaints of PPROM.

\section{Exclusion Criteria}

1. Multiple pregnancy.

2. Intrauterine growth restriction.

3. Foetal anomalies.

4. Obstetrical indications for immediate delivery.

5. Previous surgery.

6. Other causes of oligohydramnios except PROM.

Statistical analysis was done. Descriptive data were presented as mean \pm SD and range values. Chi square test was used for comparing the means of two groups. For all the tests, the probability value ( $p$ value) of less than 0.05 was considered statistically significant.

\section{RESULTS}

Incidence of PPROM was $2.6 \%$. Out of 150 cases studied, 82 $(54.6 \%)$ were in group I $(\mathrm{AFI}<5)$ and $68(45.33 \%)$ were in group II (AFI $\geq 5)$.

Mean of maternal age in group I was 23.27 and for group II was 23.91 with SD 3.6 and 3.5 respectively, so no significant difference statistically in both the groups (P value 0.827). There was no significant difference in parity in both groups (P value 0.386).

The Mean gestational age at the time of admission in group I $(\mathrm{AFI}<5)$ was 32.10 weeks and was 32.24 weeks in group II (AFI $\geq 5)$ with SD 2.26 and 2.28, difference between the two groups is not statistically significant ( $p$ value 0.0843 ).

Group I (AFI<5) exhibited a mean of 33.25 with SD 2.19 and group II (AFI $\geq 5$ ) exhibited a mean of 34.48 weeks with SD 2.09 at the time of delivery. The difference was not statistically significant in both the groups ( $p$ value 0.076 ).

Latency was significantly shorter in group $\mathrm{I}(\mathrm{AFI}<5)$ than in group II (AFI $\geq 5$ ) with a p value of 0.001 for latency period $<48$ hours.

Although the signs of clinical chorioamnionitis in group I $(\mathrm{AFI}<5)$ was $2.4 \%$ and $1.5 \%$ in group II $(\mathrm{AFI} \geq 5)$, there was no significant difference between the two groups $(\mathrm{p}=0.125)$.

Rate of abruption was $6.09 \%$ in group I and $1.4 \%$ in group II, but there was no significant difference between both groups as $\mathrm{p}$ value was 1.584. Total no. of maternal sepsis cases were higher in group I (3.6\%) as compared to group II $(1.4 \%)$. Out of 150 cases. $112(74.66 \%)$ delivered vaginally and $38(25.33 \%)$ delivered by LSCS. Foetal distress was most common indication in group I, whereas failed induction was most common cause of LSCS in group II (P value - 0.004).

No. of neonates with first minute APGAR score $\leq 7$ was significantly higher in group I $(\mathrm{AFI}<5)$ compared to group II $(\mathrm{p}=0.001)$. Whereas $5^{\text {th }}$ minute APGAR score $\leq 7$ was more in neonates of group I but it was not significant ( $p$ value-0.845).

\begin{tabular}{|c|c|c|c|}
\hline Variable & AFI $<5$ & AFI $\geq 5$ & Significance \\
\hline Maternal age & $23.27 \pm 3.6$ & $23.91 \pm 3.5$ & $\begin{array}{c}\text { Not } \\
\text { significant }\end{array}$ \\
\hline Nulliparous & 34 & 33 & $\begin{array}{c}\text { Not } \\
\text { significant }\end{array}$ \\
\hline Multiparous & 48 & 35 & $\begin{array}{c}\text { Not } \\
\text { significant }\end{array}$ \\
\hline $\begin{array}{c}\text { Gest. Age at } \\
\text { admission }\end{array}$ & $32.10 \pm 2.26$ & $32.24 \pm 2.28$ & $\begin{array}{c}\text { Not } \\
\text { significant }\end{array}$ \\
\hline $\begin{array}{c}\text { Gest. Age at } \\
\text { delivery }\end{array}$ & $33.25 \pm 2.19$ & $34.48 \pm 2.09$ & $\begin{array}{c}\text { Not } \\
\text { significant }\end{array}$ \\
\hline $\begin{array}{c}\text { Neonatal birth } \\
\text { weight }\end{array}$ & $2150 \pm 250$ & $2220 \pm 260$ & $\begin{array}{c}\text { Not } \\
\text { significant }\end{array}$ \\
\hline \multicolumn{4}{|c|}{ Table 1. Demographic and Obstetric } \\
\hline \multicolumn{4}{|c|}{ Parameters Comparison } \\
\hline
\end{tabular}

\begin{tabular}{|c|c|c|c|}
\hline Variable & AFI $<5$ & AFI $\geq 5$ & p value \\
\hline Latency period $<48$ hours & 48 & 17 & 0.001 \\
\hline Chorioamnionitis & 2 & 1 & Not significant \\
\hline Maternal sepsis & 3 & 1 & Not significant \\
\hline c/s for foetal distress & 22 & 7 & 0.021 \\
\hline NICU admission & 67 & 37 & 0.001 \\
\hline 1st minute Apgar score $\leq 7$ & 15 & 10 & 0.001 \\
\hline Neonatal sepsis & 11 & 4 & 0.021 \\
\hline Perinatal death & 17 & 3 & 0.031 \\
\hline Table 2. Maternal and Foetal Outcome Comparison \\
\hline
\end{tabular}

\section{DISCUSSION}

Study was done on 150 patients of PPROM in OB/GYN Department of PMCH, Patna for duration of 2 years. Cases were divided in two groups on the basis of AFI after doing ultrasonography and followed till hospital stay. Newborns were also followed till hospital stay.

Incidence of PPROM in present study was $2.6 \%$. Meis et al $(1995)^{1}$ showed $3 \%$, which is slightly higher than present study.

Mean maternal age in group I was $23.27 \pm 3.6$ and in group II $23.91 \pm 3.5$. There was no significant difference between maternal age of different AFIs ( $p$ value 0.827 ). So it can be said that relation between PPROM and age of mother in different groups is insignificant.

In the present study, in group I $(\mathrm{AFI}<5)$, there were $41.46 \%$ nulliparous and $58.53 \%$ multiparous women. Whereas in group II (AFI $\geq 5$ ), 48.52\% were nulliparous and $51.47 \%$ were multiparous. The overall incidence of multigravida was higher. There was no significant relation between two groups and parity of the patient with $p$ value 0.386 .

Group-I shows mean gestational age $32.10 \pm 2.2$ weeks whereas group II shows $32.24 \pm 2.28$ weeks at the time of admission. It shows that there is no relationship between PPROM associated AFI and gestational age as both groups had similar gestational age at the time of admission ( $\mathrm{p}$ value 0.0843 ). Mean gestational age at delivery was $33.25 \pm 2.19$ weeks and $34.48 \pm 2.09$ weeks for group I and group II respectively. No significant statistical difference was observed between the two groups ( $p$ - value 0.076). Both groups had similar gestational age at the time of delivery. Borna et al (2004) ${ }^{11}$ and Fatemah et al (2008) ${ }^{12}$ showed similar results. 
In present study, latency period (duration of onset of PPROM and delivery) was significantly different between the two groups. In group I (AFI<5), 58.5\% of cases delivered during the first 48 hours and only $3.6 \%$ of pregnancies were prolonged by more than 2 weeks. However, in group II (AFI $\geq 5$ ), $25 \%$ of patients delivered during the first 48 hours and $25 \%$ of pregnancies were prolonged by more than 2 weeks. Whereas in study by Borna et al $2004^{11}$ the latency period was observed to be equal in both groups. Fatemah Tavassoli et al (2008) reported that there was decreased latency period with decreased liquor which is consistent with present study.

Present study showed signs of clinical chorioamnionitis, in group I $(\mathrm{AFI}<5) 2.4 \%$ and in group II $(\mathrm{AFI} \geq 5) \quad 1.5 \%$, there was no significant difference between the two groups $(p=0.125 \%)$. Mercer et al $(2006)^{5}$ showed that there was no relationship between chorioamnionitis and PPROM related oligohydramnios. Piazze et al 200712 did not find any correlation between the two groups although $66 \%$ of cases exhibited chorioamnionitis at $\mathrm{AFI}<5$; however, they reported a significant relationship between higher maternal WBC and fever (temperature $>38^{\circ} \mathrm{C}$ ) with oligohydramnios.

In group I $(\mathrm{AFI}<5)$, the most common indication of LSCS was Foetal distress ( $p$ value 0.021). Failure of induction was the most common indication of LSCS in group II. (P value 0.004). Both were significant. Vermillion et al $2000^{13}$ showed similar results where foetal distress was the commonest indication of LSCS in group I. $18.3 \%$ vs. $4.3 \%$ in group II (P value 0.01)

No. of neonates with first minute Apgar score $\leq 7$ was significantly higher in group I $(\mathrm{AFI}<5)$ compared to group II $(p=0.001)$. So it is clear that in present study oligohydramnios due to PPROM affected $1^{\text {st }}$ minute Apgar score. This is in accordance to the study conducted by Chauhan et al 199915 who documented higher incidence of low Apgar scoring in patients with oligohydramnios.

As there was similar gestational age at the time of delivery neonatal weight was almost same in present study in both the groups. Mean birth weight in group I was $2150 \mathrm{~g} \pm$ $250 \mathrm{~g}$ and in group II was $2220 \pm 260 \mathrm{~g}$, hence no statistical significance comparing the both groups ( $p$ 0.768). Overall the mean birth weight was $2200 \pm 331 \mathrm{~g}$.

All babies were sent to NICU for evaluation. Out of which 104 were admitted for different indications. Out of 104 NICU admission; 67 were of group I and 37 were of group II. Rate of hospitalisation was higher in group I (81.7\%), then group II (54.4\%), and it was significant with (p value 0.001) Fatemah et al (2008) showed similar results with NICU admission 81.9 $\%$ vs. $71.6 \%$ in group I and group II respectively ( $\mathrm{p}$ value 0.029 ). The duration of stay for $>1$ week was significantly higher in group I as compared to group I ( $\mathrm{p}-0.011)$.

This study showed rate of sepsis in PPROM 10\%. Out of total cases, $73.33 \%$ were from group I and $26.6 \%$ from group II, after comparison rate of sepsis was higher in group I as compared to group II (P value 0.021).

The overall rate of perinatal death was 20 (13.33\%). Out of total perinatal deaths, 17 deaths $(82.35 \%)$ were recorded for group I $(\mathrm{AFI}<5)$, while $3(17.64 \%)$ deaths were observed in group II ( $\mathrm{AFI} \geq 5)$. Therefore, the rate of perinatal death was significantly higher in group I ( $p$ value 0.031 ).

\section{CONCLUSION}

PPROM with $\mathrm{AFI}<5$ has poor foetomaternal outcome in terms of latency period which is shorter than group II, more number of LSCS due to foetal distress than group II, poor first minute Apgar score, number of NICU admissions higher than group II, more early neonatal sepsis, and more perinatal deaths. To prevent this untoward outcome for the neonate and for the mother as far as possible, we can use AFI as a monitoring tool.

\section{REFERENCES}

[1] Meis PJ, Ernest JM, Moore ML. Causes of low birth weight births in public and private patients. Am J Obstet Gynecol 1987;156(5):1165-8.

[2] Smith CV, Greenspoon J, Phelan JP, et al. Clinical utility of the nonstress test in the conservative management of women with preterm spontaneous premature rupture of the membranes. J Reprod Med 1987;32(1):1-4.

[3] Gonen R, Hannah ME, Milligan JE. Does prolonged preterm premature rupture of the membranes predispose to abruptio placentae? Obstet Gynecol 1989;74(3 Pt 1):347-50.

[4] Cox SM, Leveno KJ. Intentional delivery versus expectant management with preterm ruptured membranes at 30-34 weeks' gestation. Obstet Gynecol 1995;86(6):875-9.

[5] Marino T. Ultrasound abnormalities of the amniotic fluid membranes, umbilical cord, and placenta. Obstet Gynecol Clin North Am 2004;31(1):177-200.

[6] Mercer BM, Arheart KL. Antimicrobial therapy in expectant management of preterm premature rupture of the membranes. Lancet 1995;346(8985):1271-9.

[7] Everette MF, Doherty DA, Chauhan SP, et al. How well do the amniotic fluid index and single deepest pocket indices (below the 3rd and 5th and above the 95th and 97th percentiles) predict oligohydramnios and hydramnios? Am J of Obstet and Gynecol 2004;190(1):164-9.

[8] Lawrence L, Albuquerque NM, David A. Isolated oligohydramnios at term- is induction indicated. The journal of fam practice 2005;54(1):25-32.

[9] Piazze J, Anceschi MM, Cerekja A, et al. Validity of amniotic fluid index in preterm rupture of membranes. J Perinat Med 2007;35(5):394-8.

[10] Borna S, Borna H, Khazardoost S, et al. Perinatal outcome in preterm premature rupture of membranes with amniotic fluid index $<5(\mathrm{AFI}<5)$. BMC Pregnancy Childbirth 2004;4(1):15.

[11] Tavassoli F, Ghasemi M, Mohamadzade A, et al. Survey of Pregnancy Outcome in Preterm Premature Rupture of Membranes with Amniotic Fluid Index $<5$ and $\geq 5$. OMJ 2010;25(2):118-23.

[12] Vermillion ST, Kooba AM, Soper DE. Amniotic fluid index values after preterm premature rupture of the membranes and subsequent perinatal infection. Am J Obstet Gynecol 2000;183(2):271-6.

[13] Chauhan SP, Doherty DD, Magann EF, et al. Amniotic fluid index vs single deepest pocket technique during modified biophysical profile: a randomized clinical trial. Am J Obstet Gynecol 2004;191(2):661-7. 